\title{
CANARIAS EN LAS PRIMERAS PELÍCULAS EN COLOR. LAS ISLAS EN EL CATÁLOGO DE LA COMPAÑÍA KINEMACOLOR
}

\author{
Natalia Vías Trujillo
}

\section{RESUMEN}

El sistema británico Kinemacolor fue el primero en alcanzar el éxito comercial en la captura directa del color. Mediante este proceso mecánico-fotográfico, los fotogramas en blanco y negro quedaban impresionados de forma sucesiva a través de dos filtros de color (rojo y verde), y con posterioridad, proyectados a través de luces de los mismos tonos, para producir imágenes en color gracias a la cualidad aditiva del color-luz. El primer catálogo Kinemacolor, publicado en 1913, reunía películas de ficción y documental, entre las que encontramos películas de viajes rodadas alrededor del mundo. España fue uno de los destinos recorridos por los operadores Kinemacolor quienes, entre otros lugares, viajaron a las islas de Tenerife y Gran Canaria, donde rodaron las que posiblemente sean las primeras películas filmadas en color en el Archipiélago.

Palabras clave: historia del cine, cine mudo, películas en color, compañía Kinemacolor, catálogo Kinemacolor, Islas Canarias, travelogues.

\section{THE CANARY ISLANDS IN THE KINEMACOLOR CATALOGUE. THE FIRST COLOR FILMS}

Abstract

The British Kinemacolor was the first direct color capture filming system to achieve commercial success. Through this mechanical-photographic process, successive black and white frames were impressed through two color filters (red and green), and later, projected through the same coloured lights to produce color images taking advantage of the additive nature of light colours. The first Kinemacolor catalogue, published in 1913, included fiction and documentary films. Among this pictures we find several travel films shot around the world. Spain was one of the countries visited by the Kinemacolor camera operators who, among other destinations, traveled to the islands of Tenerife and Gran Canaria, where they filmed which are possibly the first pictures shot in color in the Islands.

Keywords: Film History, Silent Films, Color films, Natural Color Kinematograph Co, Ltd., Kinemacolor Catalogue, Canary Islands, travelogues. 
El anhelo de captar la realidad "tal cual es» ha dado alas a la búsqueda de nuevos avances que contribuyan a la evolución de la fotografía y el cine. Una vez que la técnica cinematográfica logró captar el movimiento, la aspiración de los pioneros se centró en alcanzar la reproducción directa del color y la captura del sonido. El cine desde sus comienzos tuvo siempre color y el sonido, ya durante el periodo silente, estaba presente en las salas de exhibición formando parte de la experiencia cinematográfica.

En el año 2012 la prensa británica se hacía eco de un hallazgo que aportaba un nuevo y decisivo destello al brumoso periodo de los primeros años del cinematógrafo. Un prometedor titular de la BBC rezaba así: «World’s first color film footage viewed for first time»" («El primer metraje en color del mundo visto por primera vez»).

Los conservadores del National Science and Media Museum de Bradford (Inglaterra) descubren en el archivo fílmico de dicha entidad la primera película realizada en color de la historia del cine. La cinta Parrot on Perch and Goldfish in Bowl, rodada en 1902 por el pionero del cine británico Edward Raymond Turner (18731903), presentaba la novedad de haber sido filmada por medio de una cámara que incorporaba filtros en discos rotatorios de tres colores: azul, verde y rojo ${ }^{2}$. El paso del fotograma era inusual para la época, $38 \mathrm{~mm}$ con una perforación a cada lado del $\mathrm{mismo}^{3}$. Cada fotograma en blanco y negro era impresionado por la cámara alternativamente mediante cada uno de los filtros, azul, verde y rojo, que, al unirse al ser proyectados, daban como resultado la imagen en color. Mediante este proceso mecánico fotográfico, la película no tenía que someterse al, por entonces, laborioso proceso de ser coloreada a posteriori utilizando las técnicas de añadido de color a las copias en blanco y negro: el pintado a mano, el virado, el teńido o tintado y las plantillas de color ${ }^{4}$.

En declaraciones al mencionado medio de comunicación británico, Bryony Dixon, conservadora del British Film Institute (BFI), afirmaba: «Pienso que este es un paso decisivo para romper el mito de las viejas películas en blanco y negro. El $80 \%$ de las películas de entre 1890 y 1920 estaban deliberadamente coloreadas ${ }^{5}$.

${ }^{1}$ BBC News, World first colour film footage viewed for first time (12 September 2012), <https:// www.bbc.com/news/uk-england-19557914> (3/7/2020).

${ }^{2}$ En 1897 Hermann Isensee patenta en Berlín el primer procedimiento de captura de imágenes en color con el uso de filtros de color rojo, azul y verde. Turner desarrolla el sistema de Isensee como lo haría Urban posteriormente con el suyo. Timeline of Historical Film Colors. Barbara Flueckiger, Department of Film Studies. University of Zurich, <https://filmcolors.org/timeline-entry/1219/> (25/8/2020).

3 Dato extraído de Bailey, John, ASC. (2012). Two early color tests. American Cinematographer, <https://ascmag.com/> (26/7/2020).

4 Técnicas de coloreado a mano fotograma a fotograma muy en boga desde la década de 1890 hasta mediados de los ańos veinte del siglo xx.

5 Declaraciones contenidas en BBC News, 2012. 
Debido a una leve y perceptible falta de sincronicidad entre las imágenes en movimiento y el color, al ser visionadas hoy día, estas primeras imágenes rodadas por Turner mantienen un cierto halo irreal. En esta primera película el color parece tender a escabullirse, evadirse por momentos del contorno de las figuras, dando a las imágenes cierta apariencia evanescente. Turner capturó para siempre la imagen espectral de sus hijos ${ }^{6}$ jugando en el jardín de la casa familiar en Hounslow, a las afueras de Londres.

Su sistema fotográfico, patentado en 1899 , fue financiado por otro pionero del cine británico, Charles Urban (1867-1942), quien, debido al prematuro fallecimiento de Turner, hereda su invento y lo desarrolla.

Charles Urban, norteamericano afincado en Inglaterra, representa junto al inventor londinense George Albert Smith (1864-1959), impulsores ambos de la escuela de Brighton ${ }^{7}$, dos de las figuras que más decisivamente contribuyeron al desarrollo del cine británico durante la época victoriana ${ }^{8}$.

Ambos exploran la senda entreabierta por Turner y en 1906 patentan el Kinemacolor ${ }^{9}$. Un sistema que se convertirá en monopolio de éxito del cine en color durante los primeros años de la década de los diez, y que lanzarán comercialmente a partir de 1909 a través de su compañía Natural Color Kinematograph Co, Ltd ${ }^{10}$, cuyos estudios establecieron en las ciudades de Brighton, en Inglaterra, y Niza, en Francia.

Este sistema aditivo del color, de captura de las imágenes mediante el sistema Kinemacolor, se basaba en la utilización en la cámara cinematográfica con dos filtros rotatorios de color rojo y verde que incidían sobre un negativo blanco y negro. En el momento de la exhibición, el aparato proyector, que permitía tanto la proyección en color como en blanco y negro, también debía de incluir ambos filtros para la reproducción del color. La película se proyectaba a 32 fotogramas por

${ }^{6}$ Alfred Raymond Turner, Agnes May Turner y Wilfred Sidney Turner.

7 La Escuela de Brighton (Brighton School), denominada así por el historiador cinematográfico francés George Sadoul, englobaba a un grupo de cineastas quienes, entre 1896 y 1910, dan un impulso decisivo a la técnica y narrativa cinematográfica británica. A ella pertenecían fotógrafos y cineastas como George Albert Smith, James Williamson, Charles Urban y William Friese-Greene.

${ }^{8}$ Cuando hablamos de cine de la época victoriana nos referimos al periodo comprendido entre la presentación del cinematógrafo Lumière en París en 1895 y el fallecimiento de la reina Victoria en 1901. En Who's Who at the Victorian Cinema, los historiadores Stephen Herbert y Luke McKernan lo retrotraen hasta la década de 1870, ya que, según ambos historiadores, el comienzo del cine no puede datarse en una fecha específica, $<$ https://www.victorian-cinema.net/> (10/7/2020).

${ }^{9}$ El 26 de febrero de 1908 se celebra en el Palace Theatre of Varieties la primera proyección pública en Londres del sistema Kinemacolor. El 11 de diciembre de 1909 se presenta en el Concert Room del Madison Square Garden en Nueva York. La presentación estuvo a cargo de Albert Smith y Charles Urban. A Visit to the Seaside, rodada por George Albert Smith en 1908 y de 8 minutos de duración, supuso el primer éxito para la compañía.

10 La sede británica de la Compañía estaba ubicada en Kinemacolor Building, 80-82. Wardour Street. London, W. 
segundo, en lugar de la velocidad habitual de 16 fotogramas por segundo ${ }^{11}$. El sistema era explicado con estas palabras por la propia Compañía ${ }^{12}$ :

For a proper realization of the astounding advance made by Kinemacolor in the art of the camera, it must be clearly emphasized that the colors obtained are due to the agency of «light only». No painting, handwork, stencil work or similar devices are used. The colors are, as it were, lying latent in the photographic picture, and are brought into visibility at the moment of exhibition (Kinemacolor Catalogue: 1913: 5).

(Para darse realmente cuenta del impresionante avance que supone el sistema Kinemacolor en el arte de la cinematografía hay que tener muy presente que los colores son obtenidos solamente a través de la luz. No hay pintura, trabajo manual, plantillas, ni otro recurso similar. Los colores están latentes en el negativo fotográfico y se hacen visibles en el momento de la proyección).

Bajo promesa de la captura real de todos los «asombrosos y maravillosos colores de la naturaleza $»^{13}$, el Kinemacolor presentaba al público de la década un variado programa de películas: largometrajes y cortometrajes de ficción, documentales históricos, de naturaleza y de viajes ${ }^{14}$. Estos últimos, denominados travelogues, rodados por los operadores de Kinemacolor alrededor del mundo ${ }^{15}$, eran exhibidos desde mediados de los años diez ante concurridos auditorios. Las sesiones de exhibición de los travelogues eran habitualmente programadas para ser acompañadas de conferencias (lectures) que hacían las veces de explicación a las imágenes, al tiempo que amenizaban la proyección de las «vistas» de aquellos lugares lejanos y exóticos, soñados e inaccesibles para la mayoría de la población.

En 1912, la prensa cinematográfica The Moving Picture News se hacía eco en una breve reseña de la celebración en Estados Unidos de una de estas sesiones cinematográficas. Un programa muy especial, de gran potencia narrativa y presentado mediante el novedoso sistema del Kinemacolor. «El programa ofrecido esta semana -señalaba la publicación- es probablemente el más memorable de los exhibidos

${ }_{11}$ Debido a que pasaba por el proyector un fotograma a través del filtro rojo y otro a través del verde. El tamaño del fotograma y su perforación era el estándar para la época.

${ }_{12}$ Su funcionamiento fue presentado y explicado por Charles Urban y Albert Smith a científicos y fotógrafos reunidos en la Royal Society of Arts (RSA) de Londres en 1908.

13 «Kinemacolor presents all the gracious and gorgeous tints of nature» extracto del Globe newspaper, London, recogido por el catálogo en su página 105 para publicitar el sistema.

${ }_{14}$ El catálogo Kinemacolor incluye en su índice de materias (pp. 313 a 318) las siguientes: Travel and Scenic (Viajes y vistas); Naval and Military (Naval y Militar); Drama and Comedy (Drama y Comedia); State Ceremonies (Ceremonias de Estado); Natural History-Scientific and Botanical (Historia Natural-Científica y Botánica); Trick Subjects (Trucajes); Sport (Deportes); Miscellaneuos (Miscelánea); Royal Visit to India (Visita Real a la India). Además de añadir un índice con el listado de las ilustraciones contenidas en el catálogo indicando su página correspondiente.

${ }^{15}$ Los operadores de la compañía Kinemacolor, entre ellos el fotógrafo John McKenzie, recorrieron Europa, Argelia, India, Egipto, Sudán, Canadá, Nueva Zelanda, Estados Unidos, Australia y Japón. 
hasta ahora por Kinemacolor» ${ }^{16}$. El público norteamericano tuvo oportunidad de admirarse ante las imágenes de una gran tormenta desatada en el mar y cuyas olas rompían con violencia en la costa de la isla de Tenerife ${ }^{17}$. Quienes asistieron a dicha sesión fueron testigos de la proyección de una tormenta fotografiada en plena furia devastadora ${ }^{18}$, lo que para el catálogo significaba «seguramente un triunfo del arte cinematográfico» y que se mostraba ante sus ojos en sus "colores naturales». Dichas imágenes fueron captadas por los operadores de Kinemacolor gracias a un sistema que permitía al espectador disfrutar de una experiencia cinematográfica más real, más vívida y absolutamente novedosa para un público que recogía con admiración (y bastante naturalidad) el devenir de los extraordinarios y vertiginosos avances técnicos que se estaban produciendo desde mediados del siglo XIX. En palabras del historiador y conservador de la British Library, Luke McKernan: «El Kinemacolor fue la maravilla de su época» (McKernan, 2017: 32).

The Great Storm at Teneriffe integraba, junto a otras películas rodadas alrededor del mundo, el primer catálogo Kinemacolor publicado en 1913 por la compañía británica The Natural Color Kinematograph Co., Ltd. Bajo el título Animated Scenes in Their Actual Colors ("Escenas animadas en sus colores reales») el catálogo se conserva, y se encuentra disponible para su consulta, gracias a la McGill University Library de Montreal (Canadá) ${ }^{19}$.

Los catálogos de ventas de estas grandes compañías eran ofrecidos a las empresas de exhibición que se hacían con los derechos de las patentes para su explotación comercial. Los operadores de Kinemacolor añadían continuamente nuevo material cinematográfico a sus catálogos y las películas eran exhibidas en las salas Kinemacolor de medio mundo. Como el mismo catálogo señala en una nota aclaratoria en su página 14, el número de registro de las películas ofrecidas en él guarda relación con el orden de llegada de los negativos que se recibían fruto del trabajo de los operadores y que progresivamente iban añadiéndose y completando el catálogo. Por lo tanto, a través del estudio de las características de las películas que se

16 The Moving Picture News, volume vi, n. ${ }^{\circ}$ 15, October 12, 1912, Something about Kinemacolor Releases, p. 26. En la hemeroteca digital: Latern, search, visualize $\&$ explore the media history digital Library, <https://lantern.mediahist.org/> (18/6/2020).

${ }_{17}$ Desde finales del siglo XIX, las películas rodadas por, entre otros, Robert Paul (18691943) o Birt Acres (1854-1918), que captaban las olas del mar rompiendo contra la costa, fueron las más celebradas por el público victoriano. Las imágenes del mar, sin trucajes y de gran potencia visual, alcanzaban un gran poder de fascinación para el espectador decimonónico. Rough Sea at Dover, rodada en 1895 por Birt Acres, es unas de las películas británicas más antiguas conservadas.

${ }^{18}$ Se detalla en el catálogo como los operadores fueron testigos de la devastación que ocasionó la tormenta en Tenerife y observaron el casco medio sumergido del buque S.S. Tillus, que encalló en la costa debido a la tormenta.

${ }^{19}$ Catalogue of Kinemacolor Film Subjects: Animated Scenes in Their Actual Colors. The Natural Color. Kinematograph. Co, Ltd, London, 1913. Digitalizado por McGill University Library, Toronto (Canadá) el 25 de octubre de 2017. Título de la cubierta: Kinemacolor Film Catalogue 1912-1913. Consta de 318 páginas, 32 páginas con láminas de ilustraciones en color (64 ilustraciones $\times 24 \mathrm{~cm}$ ). Consultar en $<$ https://archive.org/ $><$ https://archive.org/details/McGillLibrary-rbsc catalogue-kinemacolor_ColgateIXNaturalColor-17612/mode/2up $>$. 
encuentran recogidas en el mismo, podríamos estudiar el interesante desarrollo del propio sistema Kinemacolor, que denota un dominio progresivo de la técnica del color y del lenguaje cinematográfico. Esto se pone de manifiesto cuando establecemos la comparativa entre las primeras películas que se ofrecen en el catálogo, de contenidos más costumbristas, como la primera cinta que lo integra: $A$ Visit to the Seaside (n. ${ }^{\circ} 101,1.035$ feet, páginas 16 y 17 del catálogo), una "vista» rodada en la costa inglesa de Brighton, que se circunscribe al apunte de ciertos detalles del paisaje y en describir las escenas de un plácido día de estancia de unos niños en la costa, de los que el catálogo se vanagloriaba de haber captado «tal cual se ven en la naturaleza»; y el contenido de otras películas más ambiciosas como las que los operadores Kinemacolor rodaron en las ceremonias de Estado. Entre estas últimas se incluye el extraordinario documental de Urban The Coronation Durbar at Delhi, December 12th $1911^{20}$ (n. ${ }^{\circ}$ 507, 3.240 feet, páginas 295 a 299 del Catálogo), una de las películas sobre el subcontinente indio que aparecen recogidas bajo el título The Royal Visit to India 1911-1912, y que fueron rodadas durante el viaje de estado del Rey Jorge V de Inglaterra (1865-1935) y la reina Mary of Teck (1867-1953) entre el 2 de diciembre de 1911 y el 8 de enero de 1912, en el que visitaron las ciudades de Bombay, Delhi y Calcuta (pp. 280 a 310 del catálogo ${ }^{21}$.

El periódico The Times recogía la noticia de la partida de Charles Urban, acompañado de siete de sus operadores, hacia el país del Ganges. Urban fue designado por el propio monarca para llevar a cabo el rodaje de las fastuosas ceremonias reales $^{22}$. La repercusión de los documentales rodados por Urban y su equipo quedó reflejada en algunos de los periódicos de más prestigio de Gran Bretaña: The Times, Sunday Times, Financial News, Telegraph, Daily News y recogidos, como medio de publicitar las películas, por el catálogo en sus páginas 310, 311 y 312 bajo el título Press notices relating to the series... With our King and Queen through India.

Celebradas fueron también las películas que bajo el título The Egyptian Series rodaron los operadores Kinemacolor en Egipto ${ }^{23}$. Esta serie de documentales travelogues que recorrían el país del Nilo de norte a sur con una finalidad -según apunta el propio catálogo- educativa, y para los que la compañía estuvo asesorada por repre-

${ }^{20} \mathrm{Su}$ estreno tuvo lugar en Londres el 2 de febrero de 1912 en el teatro de la Scala (Scala Theatre). El teatro fue inaugurado en 1904. Reconvertido en cine, permaneció desde 1911 a 1918 bajo la gerencia de Charles Urban.

${ }^{21}$ Otras compañías se desplazaron a la India a rodar las ceremonias reales: The Great Coronation Durbar, Delhi 1911 (British Pathé, blanco y negro); Delhi Durbar (1911) (blanco y negro), incluidos en la colección Exploring India on Film 1899-1947, British Film Institute. Algunas de las películas conservadas se encuentran en la Cineteca de Bolonia, el archivo Russian State Documentary Film \& Photo Archive, Krasnogorsk, Russia. Consultar $<\underline{\text { https://www.charlesurban.com/ }}$ films_kinemacolor.html>.

22 The Times, November 16, 1911, «The Durbar in Kinemacolor», p. 11, <https://www. thetimes.co.uk/> (30/7/2020).

${ }^{23}$ La serie sobre Egipto está contenida en las páginas 197 a 217 del catálogo. 
sentantes de la sociedad británica de viajes Thomas Cook \& Son ${ }^{24}$, mostraban al espectador esta «maravillosa y misteriosa tierra». Los operadores de la compañía, acompañando el trazado del río Nilo, que fotografiaron de forma destacada en los atardeceres ${ }^{25}$, comenzaron un viaje de tres meses de duración, en el bajo Egipto, en el canal de Suez y la ciudad de Alejandría y viajando al sur, visitaron Assuán, Luxor y Karnak, llegaron a Nubia y la segunda catarata para finalizar el recorrido en Jartum, la legendaria capital de Sudán, donde el Nilo blanco se encuentra con el Nilo azul26. El catálogo de la compañía The Natural Color Kinematograph. Co, Ltd. 1913, bajo patente Urban-Smith, reúne asimismo diversos travelogues rodados en países tan lejanos entre sí como Argelia, Estados Unidos, Canadá, Bélgica, Italia, Gran Bretaña o Constantinopla (actual Estambul) cuyo índice las engloba bajo el subtítulo Travel and Scenic ${ }^{27}$ y en el que también encontramos recogidas las películas rodadas por Kinemacolor en las Islas Canarias.

Las películas que constan en el catálogo Kinemacolor como rodadas en Canarias son las siguientes:

N. 220 The Great Storm at Teneriffe. Canary Islands $\left(740 \mathrm{feet}^{28}\right)$.

(Página del catálogo :104)

N. 222 Scenes in Santa Cruz, Teneriffe (By Courtesy of the Union-Castle Steamship Company) (850 feet).

Synopsis:

1. Teneriffe.

2. The Union-Castle Steamship.

3. A Pinacce.

4. Taking Observations.

5. A Small Boat.

6. General Views.

7. A Rowing Boat.

8. Santa Cruz: Scenes on the Quay.

9. Boys Paddling.

10. A Rainbow.

11. Street Scenes.

(Páginas del catálogo: 104 y105)

${ }^{24}$ Thomas Cook \& Son fue una compañía británica de viajes fundada por Thomas Cook (1808-1892) en el año 1841 en Leicester, Inglaterra.

${ }^{25}$ Las imágenes de todos los atardeceres rodados en Egipto fueron recogidas en la película titulada Sunsets in Egypt (n. ${ }^{\circ} 378,485$ feet), páginas 216 y 217 del catálogo.

${ }^{26}$ En los fondos del British Film Institute y de la Cineteca de Bolonia se conservan algunas de estas películas rodadas en Egipto.

27 Las películas rodadas en las Islas Canarias contenidas en el apartado Travel and Scenic abarcan las páginas 104 a 110 del catálogo.

${ }^{28}$ La longitud del celuloide está señalada en pies (feet). 
N. ${ }^{\circ} 223$ San Andres and La Orotava, Teneriffe (By Courtesy of the Union-Castle Steamship Company) (710 feet).

Synopsis:

1. San Andres

2. A General Panorama.

3. The Town.

4. A Curious Structure.

5. Island Scenes.

6. A Group of Natives.

7. A Palm Bordered Road.

8. A Rainbow.

(Página del catálogo: 106)

N. 224 Cave Dwellers of Atalaya. Grand Canary (700 feet).

(Páginas del catálogo: 107 y 108)

N. ${ }^{\circ} 225$ On a Banana Plantation (915 feet)

Synopsis:

1. A Plantation of Young Palms.

2. The Bunches of Young Fruit.

3. Bunches Ready for Cutting.

4. Large Bunch of Bananas.

5. Packing the Fruit.

6. Women Workers.

7. Packing the Bunches.

8. A Crate of Fruit ${ }^{29}$.

9. A Van Loaded.

10. The Employees.

11. Loading the Steamers.

12. Two Youthful Natives.

13. Monkey Eating a Banana.

(Páginas del catálogo: 108 y109)

N. 226 A Tram Ride through Las Palmas (280 feet).

(Página del catálogo: 109)

${ }^{29}$ En este apartado el catálogo relata las imágenes de la preparación de la fruta lista para su exportación por los Sres. Lyffe, los exportadores, explica el catálogo, más importantes de plátanos en las islas. 
N. 227 Scenes at Las Palmas. Gran Canary (1060 feet).

Synopsis:

1. Arrival at Grand Canary.

2. Deep Sea Divers.

3. Panorama of Las Palmas.

4. Street Scenes.

5. Local Types.

6. Spanish Soldiers.

7. Boat-Building.

8. Merchants and their Wares.

9. Ploughing by Oxen.

10. Beach Scenes.

(Página del catálogo: 110)

La compañía señalaba a The Great Storm at Teneriffe como un «soberbio modelo de fotografía marina y un excepcional ejemplo de la cualidad translúcida del agua» (Kinemacolor Catalogue, 1913: 104). El catálogo Kinemacolor destacaba asimismo el interés y la belleza de las películas rodadas por sus operadores en Tenerife y Gran Canaria. Incluyendo incluso algún detalle sobre la forma en que las imágenes fueron rodadas, el catálogo describía con detalle el contenido de cada «vista». Las imágenes comprendidas en la película A Tram Ride Through Las Palmas fueron tomadas en la parte trasera de un tranvía en movimiento, con lo que «las curiosas edificaciones y los vehículos que pasaban eran de pleno interés» (Kinemacolor Catalogue, 1913: 109).

Es conocida la fascinación de los pioneros por el movimiento de los trenes y tranvías. En el propio viaje en tren, el paisaje en movimiento enmarcado por la ventanilla (una suerte de encuadre, de límite físico entre nuestra mirada y el objeto de la misma) nos presenta un simulacro de experiencia cinematográfica. Desde los inicios del cinematógrafo, los operadores colocaban sus pesadas cámaras en tranvías, automóviles, embarcaciones, globos aerostáticos, trineos, e incluso, como hizo el propio Alexandre Promio (1868-1926), operador de Lumière, sobre una góndola ${ }^{30}$, a fin de que las imágenes se movieran, «viajaran» libremente, captando un movimiento continuo. Este género de películas, denominado muy acertadamente Phantom Ride o Panoramas, fascinaba al público británico y norteamericano de finales del xix. Gracias a esta nueva perspectiva dinámica, el espectador era testigo del mundo que se movía a su alrededor, la vida que fluía a su misma velocidad y, en el caso del tranvía, casi a la altura de sus ojos.

La experiencia cinematográfica a través de la evolución de la técnica tendería progresivamente a una forma de expresión más realista. Se acercaría a lo que el teórico galo André Bazin (1918-1958) denominaría el «realismo integral». En pala-

${ }^{30}$ Panorama du Grand Canal pris d'un bateau (Alexandre Promio, 1896). 
bras del propio Bazin, a una «recreación del mundo a su imagen, una imagen sobre la que no pesaría la hipoteca de la libertad de interpretación del artista ni la irreversibilidad del tiempo» (Bazin, 2004: 37).

Esta aspiración de los cineastas e inventores de los orígenes daba apoyo a la compañía Kinemacolor para publicitar sus películas:

Only by Kinemacolor can full justice be done to panoramic and scenic subjects, because the system is the only one which provides the realistic qualities necessary to their full and adequate treatment. Those pictures secured by the Urban-Smith process from a railway engine platform, from an aeroplano, a torpedo boat, or any other swiftly-moving conveyance, furnish absolutely faithful reproductions of the actual scenes, and lend practically the true sense of motion. Thus presented, the brilliantly illuminated Kinemacolor pictures are pictures no longer, but realities which afford to the comfortably-seated audience the sensation of viewing the actual scenes through a window. (Kinemacolor Catalogue, 1913: 9).

(Solamente con Kinemacolor se puede hacer justicia a las vistas y paisajes, porque el sistema es el único que provee de las cualidades realistas necesarias para su adecuado trato. Estas imágenes garantizadas por el proceso Urban-Smith rodadas desde una plataforma de la máquina de una locomotora, un aeroplano o un barco lanzatorpedos o cualquier otro transporte en movimiento, reproduce con absoluta fidelidad las escenas reales y provee de la verdadera sensación de movimiento. Así presentado, las brillantemente iluminadas imágenes Kinemacolor ya no son imágenes, sino realidades que ofrecen a un público confortablemente sentado, una sensación de ver escenas reales a través de una ventana).

En el catálogo Kinemacolor no solo se da algún detalle de cómo se tomaban las imágenes, también de la calidad o las características de la imagen en sí. En la película Scenes at Las Palmas, Gran Canary, el catálogo aprecia, en la toma de una panorámica sobre la ciudad, su destacable calidad "estereoscópica», es decir, la gran profundidad conseguida en esta imagen por los operadores Kinemacolor.

Si el catálogo abría su oferta de películas rodadas en Canarias con la mencionada gran tormenta en la costa de Tenerife, este ofrecía para cerrar las películas disponibles sobre las islas, bajo el subtítulo Beach Scenes, algunas escenas rodadas en una playa de Gran Canaria. Una escena que, al leer su descripción en el catálogo, parece casi idílica: las vistas de un mar en calma y la imagen de unos lugareños cargando con arena de la playa los cestos que porta un burrito. Además, la imagen de unas mujeres que rompen piedras en la orilla para hacer un sendero evidencian, según el texto del catálogo, el atraso de las islas debido al duro trabajo manual que realizaban las mujeres tanto a orillas del mar como la dura faena en las plantaciones de plántanos.

Estas imágenes del mar, las embarcaciones y el trabajo de los estibadores en el puerto están siempre presentes aunque también los operadores Kinemacolor captaron la vida de los habitantes de las ciudades y pueblos de Tenerife (Santa Cruz, San Andrés, La Orotava) y Gran Canaria (La Atalaya, Las Palmas).

Entre los siete títulos sobre las islas que integran este catálogo encontramos muchos de los valores paisajísticos que las han hecho desde siempre enormemente 
atractivas tanto para los cineastas como para los fotógrafos de todas partes del mundo: las tonalidades de las coladas de lava, el mar y el cielo límpido de las islas, la luz del alba y el crepúsculo, el verde de las extensiones de cultivo y de los valles, la perfecta simbiosis de las gentes y la naturaleza y los paisajes de gran carga telúrica admirados por ojos foráneos. Así, el catálogo remarca los maravillosos contrastes de color poniendo énfasis en los tonos del mar y el cielo, de los acantilados y los valles. ¿Estamos en definitiva ante las primeras películas rodadas en color en el Archipiélago?

Dada la temprana fecha de su producción podríamos responder afirmativamente.

En la década de los años diez en Canarias el color estaba únicamente en los ojos de los pintores y las lentes de los fotógrafos. Debemos esperar hasta una década posterior para encontrar algunas de las películas más importantes de la historia del cine en Canarias que, rodadas en blanco y negro, fueron tintadas o teñidas en color: Tenerife (José González Rivero, 1922), Canarias (José González Rivero, 1923), El ladrón de los guantes blancos (José González Rivero, Romualdo García de Paredes, 1926) y La hija del Mestre (Carlos Luis Monzón, 1927) ${ }^{31}$.

La primera referencia que se data en el Catálogo de Rodajes en Canarias (1896-1950) de una película rodada en color en las islas es West Africa, Canaries, Madeira $^{32}$, un amateur travelogues de 1938. Película que fue rodada en $16 \mathrm{~mm}$, probablemente mediante el sistema de color Kodachrome ${ }^{33}$, por el operador J.N. Jeneid durante su estancia en Tenerife en un viaje organizado por la compañía británica Thomas Cook (Thomas Cook \& Son., Ltd.).

Por tanto, estas películas rodadas ya en la temprana década de los diez por la compañía Kinemacolor fueron muy probablemente las primeras rodadas en color en las Islas Canarias.

Además de las imágenes de las islas, se ofrecían en el catálogo películas documental o "vistas» rodadas en las ciudades españolas de Sevilla, Granada, Toledo y Madrid. Son las siguientes:

Seville at Carnival Time (n. ${ }^{\circ}$ 269, 460 feet, página 144 del catálogo).

H.M The King of Spain ${ }^{34}$. Reviewing recruits and regulars at Madrid, April 30th 1911 (n. ${ }^{\circ} 267,880$ feet, página 147).

Views of Old Toledo, Spain (n. ${ }^{\circ} 385,1035$ feet, páginas 221 y 222).

31 Información obtenida del Catálogo de Rodajes en Canarias (1896-1950), 2004.

32 Ibid, Catálogo de Rodajes en Canarias. Películas no profesionales extranjeras rodadas en Canarias, p. 221.

${ }_{33}$ Dato incluido en Colonial Film Catalogue, Moving images of the British Empire. The Colonial Film website is funded by the Arts and Humanities Research Council and features films from the British Film Institute, the Imperial War Museum, and the British Empire and Commonwealth Museum, <http://www.colonialfilm.org.uk/> (15/8/2020).

34 El documento muestra al rey Alfonso XIII (1886-1941) acompañado de la reina consorte Victoria Eugenia de Battenberg (1887-1969) pasando revista a las tropas en la ciudad de Madrid. 
Sunny Spain. Seville, Granada and Alhambra (n. ${ }^{\circ} 399,1225$ feet, páginas 222 y 223). Spanish Bull Fight at Madrid (n. ${ }^{\circ} 384,1015$ feet, páginas 223 y 224).

En Madrid, el 7 de mayo de 1915 fue presentado por primera vez el sistema Kinemacolor en el cinematógrafo Príncipe Alfonso ${ }^{35}$, el programa consistió en Procesión de elefantes en Calcuta y Maniobras de la escuadra inglesa ${ }^{36}$, películas que obtuvieron una gran acogida entre el público asistente a tan reseñable acontecimiento ${ }^{37}$. Unos años antes, en 1911, la revista ilustrada Alrededor del mundo dedicaba uno de sus artículos al sistema Kinemacolor destacando lo siguiente: «El Kinemacolor es la última palabra en materia cinematográfica, porque las películas tienen los colores de la realidad sin subterfugio alguno y sin recurrir a ninguno de los medios artificiales empleados para colorear, a mano o a máquina, las cintas en blanco y negro, como hasta ahora se venía haciendo ${ }^{38}$. El Kinemacolor causó gran impacto entre el público madrileño que asistía a las proyecciones diarias de este novedoso sistema publicitado como «rival de la naturaleza».

La noticia del estreno mundial del sistema Kinemacolor llega muy pronto a las Islas Canarias. En el mes de julio de 1911 el Diario de Las Palmas ${ }^{39}$ reproduce la reseña publicada tan solo unos días antes por la revista madrileña Alrededor del mundo.

Después de varios años de éxito comercial (entre 1908 y 1915), el sistema Kinemacolor pierde fuerza, resulta extremadamente gravoso de mantener para la compañía, que se encontraba además en dura pugna con el sistema Technicolor ${ }^{40}$. Este último acabará monopolizando desde los años veinte el color en la industria cinematográfica. Otros avances ocuparán el lugar del primitivo sistema Kinemacolor en la historia del cine; un sistema que fue revolucionario, de gran sencillez técnica y destreza imaginativa, que supuso un enorme empuje para los pioneros que trabajaron con dedicación para lograr hacer evolucionar el tratamiento del color en el cine e hizo avanzar de forma extraordinaria a la industria cinematográfica. En palabras

35 El Teatro Príncipe Alfonso fue inaugurado el 7 de mayo de 1863 y demolido en 1898. Fue obra del prestigioso arquitecto José María Guallart y Sánchez.

${ }^{36}$ El programa también lo integraba la película Industrias de Ceilán y un cortometraje de asunto dramático. Dato que se incluye en el blog Sr. Feliu, "Documentitos de un indocumentado», El Kinemacolor en España, <http://documentitosdeunindocumentado.blogspot.com/2018/09/el-kinemacolor-en-espana.html $>\overline{(21 / 8 / 2020) \text {. }}$

${ }^{37}$ También fue recogida la noticia del Kinemacolor en $A B C$ el 8 de mayo de 1915, p. 22 y El Pais el 9 de mayo de 1915, p. 3 entre otras publicaciones de la época $<$ http://hemerotecadigital. bne.es/> (16/8/2020).

${ }^{38}$ Alrededor del mundo, 12 de julio de 1911, «El Kinemacolor. Una maravilla cinematográfica", p.19. Biblioteca Nacional de España. Hemeroteca Digital $<$ http://hemerotecadigital.bne.es/ issue.vm?id=0001881138\&page=19\&search=kinemacolor\&lang=es $>(8 / 7 / 2020)$.

39 Diario de Las Palmas, 24 Julio 1911, «Kinemacolor. Una maravilla cinematográfica», p. 2.

40 El sistema Technicolor se presenta en 1922 y se implanta en la industria hasta entrada la década de los cincuenta. Dato extraído de Timeline of Historical Film Colors, <https://filmcolors. org/> (24/7/2020). 
del historiador Luke McKernan: «Todas las películas son fascinantes por su tenue, sobrenatural color y destacables por su estudiado valor artístico» ${ }^{41}$.

A partir de entonces, el recuerdo de las películas Kinemacolor se diluye en el tiempo y en la memoria de espectadores y especialistas hasta que, llegada la década de los ochenta, el técnico de un archivo regional de Italia deposita en la Cineteca de Bolonia una valiosa colección de nitratos. Los veintitrés títulos Kinemacolor que componen esta colección de Bolonia fueron restaurados y se encuentran actualmente conservados en los fondos de dicha entidad ${ }^{42}$.

En 2017 la Cineteca de Bolonia a través de Il Cinema Ritrovato presentó, en el Festival que se celebra cada año en la ciudad italiana, un programa de películas Kinemacolor conservadas en los fondos de su archivo fílmico, organizado en colaboración de diversos organismos como el Bristish Film Institute, EYE-Instituto de cine de Ámsterdam y los fondos de la colección John E. Allen de Estados Unidos. Además de la celebración de este programa especial, la Cineteca de Bolonia editó la colección Kinemacolor e altre magie, diez títulos Kinemacolor rodados entre 1907 y 1912, restauradas por L'immagine Ritrovata, contenidos en dos DVD y acompañados de un breve catálogo. La colección incluía además películas de las compañías Kinemacolor Comerio, Chronochrome Gaumont y Pathécolor. La iniciativa de la Cineteca de Bolonia sin duda puso en valor de nuevo el extraordinario impacto que causaron las películas Kinemacolor en su época y el legado de enorme importancia que tienen estas películas para la historia del cine. Aunque nuestra mirada sobre el mundo y nuestra apreciación acerca de las imágenes que vemos en la pantalla han variado en más de un siglo de manera indudable, el valor técnico de estas películas fue, y continúa siendo, equiparable a su calidad artística. Estas imágenes vistas hoy día parecen contemplarnos desde el otro lado de un cristal, tan lejanas y tan próximas a la vez en el tiempo y en el espacio, por momentos, evanescentes; imágenes que pretenden, y consiguen, aprehender el color. Películas como aquella Parrot on Perch and Goldfish in Bowl con la que Edmund Raymond Turner retrató a sus hijos sujetando girasoles entre sus pequeñas manos mientras observaban a un pez que nadaba en la translúcida pecera. Una ventana en el tiempo que abría un camino repleto de posibilidades.

Luke McKernan señala con gran acierto: «De la manera en que el Kinemacolor se veía realmente se ha perdido en el tiempo. Lo que veían los espectadores de entonces no es lo que vemos nosotros ahora. Delante de sus ojos se abría un mundo nuevo; nosotros vemos un mundo perdido para siempre» (McKernan, 2017: 36).

Actualmente se conservan películas Kinemacolor, además de en la citada Cineteca de Bolonia, donde se atesora la colección mas importante de nitratos del periodo comprendido entre 1908 y 1912, en archivos de Francia, Inglaterra, Holanda,

${ }^{41}$ McKernan, Luke, Discovering Kinemacolor, <https://lukemckernan.com/> (2/7/2020).

${ }^{42}$ Se conservan 23 títulos que corresponden a 6000 metros de película en 45 rollos. Dato extraído de I Colori Ritrovati. Kinemacolor e altre magie, p. 40. 
Rusia y Estados Unidos ${ }^{43}$. De los aproximadamente mil títulos que rodó la compañía Kinemacolor entre 1908 y 1917 apenas se conservan cincuenta ${ }^{44}$. Tanto la Cineteca de Bolonia a través del responsable de su archivo, Andrea Meneghelli, como el historiador Luke McKernan no han podido confirmar la existencia en sus fondos, ni en los de ningún otro archivo internacional, de alguna copia de las películas Kinemacolor rodadas en Canarias (A ambos me permito expresarles desde aquí mi agradecimiento por su ayuda).

Quizás esa violenta y asombrosa tormenta capturada cerca del litoral de Tenerife, las escenas callejeras de los pequeños pueblos y las panorámicas de los valles, el trabajo de los habitantes de las islas en las plantaciones de plátanos y en los muelles, las vistas de la cumbre del Teide cubierta de nieve, que se ofrecían en este primer catálogo de la compañía Kinemacolor, se encuentren atesoradas en algún lugar aguardando a que alguien las descubra y conserve para futuras generaciones. Podríamos entonces asistir como espectadores a las primeras películas rodadas en color en las Islas Canarias.

RECIBIDO: 28-10-2020; ACEPTADO: 5-2-2021

43 Relación de películas conservadas en archivos fílmicos. Consultar $<$ https://www.charlesurban.com/films_kinemacolor.html> (9/8/2020).

${ }^{44}$ Dato extraído de Kinemacolor e altre magie, p. 34. 


\section{BIBLIOGRAFÍA}

A Companion to Early Cinema (2012). Gaudreault, André; Dulac, Nicolas; Hidalgo, Santiago (eds.), UK: John Wiley \& Sons, Ltd.

Bazin, André (2004). ¿Qué es el cine? Madrid: Ediciones Rialp, S.A.

Braun, Marta. (2016). Early Film Colour, Today and yesterday, en Braun, Marta; O’Brien, Charles; Keil, Charlie; King, Rob; Moore, Paul \& Pelletier Louis (eds), Beyond the Screen: Institutions, Networks and Publics of Early Cinema. UK: John Libbey Publishing, Ltd.

Catalogue of Kinemacolor Film Subjects. Animated Scenes in Their Actual Colors (1913). London: Natural Color Kinematograph Co, Ltd.

Cherchi Usai, Paolo (2019). Silent Cinema; A Guide to Study, Research and Curatorship. London: The British Film Institute.

Encyclopedia of Early Cinema, (2005). Aвel, Richard (ed.), London and New York: Routledge.

I Colori Ritrovati, Kinemacolor e altre magie, (2017). Lewinsky, Mariann e McKernan, Luke (eds.), Bologna: Cineteca Bologna.

McKernan, Luke. (2017). Kinemacolor. A Short Story, Lewinsky, Mariann e McKernan, Luke (eds.), I Colori Ritrovati, Kinemacolor e altre magie (pp. 32 -36). Bologna: Cineteca Bologna.

Rodajes en Canarias (1896-1950) (2004). Gorostiza López, Jorge (coord.), Islas Canarias: Filmoteca Canaria, Viceconsejería de Cultura y Deportes, Gobierno de Canarias.

SADoul, Georges (1993). Las maravillas del cine. México: Fondo de cultura económica. 
